University at Albany, State University of New York

Scholars Archive

\title{
Knowledge building and vocabulary growth over two years, Grades 3 and 4
}

\author{
Yanqing Sun \\ University at Albany, State University of New York, ysun@albany.edu \\ Jianwei Zhang \\ University at Albany, State University of New York, jzhang1@albany.edu \\ Marlene Scardamalia \\ University of Toronto, Canada
}

Follow this and additional works at: https://scholarsarchive.library.albany.edu/etap_fac_scholar

Part of the Education Commons

\section{Recommended Citation}

Sun, Yanqing; Zhang, Jianwei; and Scardamalia, Marlene, "Knowledge building and vocabulary growth over two years, Grades 3 and 4" (2010). Educational Theory and Practice Faculty Scholarship. 10.

https://scholarsarchive.library.albany.edu/etap_fac_scholar/10

This Article is brought to you for free and open access by the Educational Theory and Practice at Scholars Archive. It has been accepted for inclusion in Educational Theory and Practice Faculty Scholarship by an authorized administrator of Scholars Archive. For more information, please contact scholarsarchive@albany.edu. 
Running Head: KNOWLEDGE BUILDING AND VOCABULARY GROWTH

Knowledge Building and Vocabulary Growth over Two Years, Grades 3 and 4

Yanqing Sun, Jianwei Zhang,

University at Albany, State University of New York

\author{
Marlene Scardamalia \\ Ontario Institute for Studies in Education of the University of Toronto
}

Corresponding author:

Yanqing Sun

Albany Institute for Research in Education

School of Education, University at Albany

Albany , NY 12222; Phone: (518) 442-5026

Fax: (518) 442-5933

Email:ysun@albany.edu 


\begin{abstract}
High-level literacy and productive knowledge work are central to educational reforms. In the research reported in this article, students were engaged in sustained, collaborative knowledge building in science and social studies. The vocabulary growth of 22 students over Grades 3 and 4 was traced, based on their entries to Knowledge Forum-a knowledge building environment used as an integral part of classroom work. It is the communal space where ideas, reference material, results of experiments, and other inquiry work are entered and continually improved. Analysis of lexical frequency profiles indicated significant growth in productive written vocabulary, including academic words.

In a Grade 4 inquiry, students incorporated almost all the domain-specific terms at and below their current grade level, and most of those expected for upper grade levels (5-8) based on the curriculum guidelines. Domain-specific and academic words were correlated with depth of understanding. High correlations between student engagement in knowledge building and vocabulary growth suggest that productive vocabulary can be developed through sustained knowledge building in subject areas.
\end{abstract}

Keywords: Knowledge building, vocabulary learning, literacy, online discourse, lexical frequency profiles 


\section{Knowledge Building and Vocabulary Growth over Two Years, Grades 3 and 4}

\section{Introduction}

Productive knowledge work and high-level literacy are essential for engagement in a knowledge society.

Modern pedagogical initiatives emphasize collaborative inquiry in content areas (e.g., science, mathematics) through

which students build deep understanding of core contents (e.g., Bransford, Brown, \& Cocking 2000; Lamon,

Secules, Petrosino, Hackett, Bransford, \& Goldman 1996; Lehrer, Carpenter, Schauble, \& Putz 2000; NRC 2000;

Zhang \& Sun 2005). Literacy involves the ability to read and write with understanding, to obtain and utilize

information from written materials in daily activities, and to use language as a tool to construct and communicate

ideas. A socio-cognitive and cultural view of literacy underlines the importance of engaging students in authentic

literacy practices that integrate language learning and language use (Applebee, Langer, Nystrand, \& Gamoran

2003). Such literacy practices extend beyond language classes and are integral to learning in all subject areas

(Applebee 1981; Bereiter \& Scardamalia 1987a; Cantoni-Harvey 1987; Connolly \& Vilardi 1989; Guthrie, Wigfield,

\& Perencevich 2004); although in current practice, many students are not writing a great deal for any of their

academic subjects (Applebee \& Langer 2006).

This study investigates an integrated process to engage students in productive knowledge work and literacy

practices--the process of knowledge building. It examines students' literacy engagement during their sustained,

collaborative knowledge building in various subject areas, focusing on the growth of their written vocabulary.

Knowledge Building

Knowledge building is a social process through which people work collaboratively to create and improve ideas

of value to their community. It is through this process that research groups produce increasingly powerful 
explanations about the world, and high-tech companies address challenging problems and develop new

technological products. The knowledge building pedagogy aims to bring this process to students and transform classrooms into knowledge building communities (Scardamalia \& Bereiter, 1994). It distinguishes itself from other collaborative inquiry learning approaches through a set of core knowledge building principles, including: epistemic agency, collective responsibility for community knowledge, and knowledge building discourse, etc. For example, the principle of epistemic agency highlights the need to turn over high-level control of knowledge work to students. Students would then be dealing with problems of goals, motivation, evaluation, and long-range planning; problems that are normally left to teachers. The principle of collective responsibility for community knowledge points to the importance of giving students' ideas a public life as "conceptual artifacts" (Bereiter, 2002) and students working as a team to continually improve those ideas, not simply advance their own. Knowledge building discourse refers to transformative discursive practices that not only lead to sharing of knowledge but sustained inquiry of deeper issues and improvement of ideas, with advancement of knowledge as its explicit goal (Scardamalia, 2002).

To support knowledge building communities, Scardamalia, Bereiter, and colleagues created the networked knowledge building environment CSILE (Computer-Supported Intentional Learning Environment) and it's secondgeneration version, Knowledge Forum (see Scadamalia 2004 for an introduction). Knowledge Forum—rooted in research of writing, expertise, and knowledge building — provides a multimedia-based knowledge space for collective works so that students can contribute ideas and build on, annotate, and rise above their early understandings. By authoring notes ${ }^{1}$, students contribute ideas, questions, empirical data, reference material, personal experiences/stories and so forth, to views, which are workspaces for various clusters of inquiry. Both notes

\footnotetext{
${ }^{1}$ The italicized words in this section represent basic features of Knowledge Forum referred to throughout this article.
} 
and views can include multimedia elements (e.g., text, graphics, video). Supportive features for knowledge building discourse allow users to co-author, build on and annotate notes of community members; create reference links with citations to each other's notes; add keywords; and create rise-above notes to summarize, distil, and advance their discussions.

In knowledge building classes, students generate problems of understanding, discuss diverse ideas and theories through face-to-face knowledge building discourse, conduct self-generated experiments, make observations, search libraries and the Internet, and understand new resources through cooperative reading. They contribute problems, ideas, data, and resources generated through face-to-face discourse, reading, experiments, etc., to a shared space in Knowledge Forum for continual improvement.

The knowledge building practices in both online and offline environments create diverse demands and opportunities for high-level literacy practices. These include deep and cooperative reading focusing on important disciplinary concepts (Guthrie et al. 2004; Scardamalia, Bereiter, Hewitt, \& Webb 1996); extensive and authentic writing that involves real and responsive audiences, focusing on idea development; and open, extended, and continuous collaborative dialogue (Applebee 1996; Bakhtin 1981; Nystrand 1997; Swain 2000). The discourse environment provided by Knowledge Forum converges with online environments specially designed for language learning in a number of design features, for example: active manipulation of information from multiple sources, generation and revision of texts, and reflective conversations involving peers, teachers, and experts (e.g., Lamy \& Goodfellow 1999; Warshchauer 2000; Zhao, Englert, Chen, Jones, \& Ferdig 2000). When such online environments are used in a way that engages students in deep processing of information in the service of authentic goals, they generally demonstrate positive motivational and cognitive effects (Warschauer 2007). A relevant earlier experimental-control study showed that students in the knowledge building classes exhibited compelling gains in 
literacy, especially vocabulary (Scardamalia, Bereiter, Brett, Burtis, Calhoun, \& Smith-Lea 1992). Further research is needed to achieve a deeper understanding of literacy advances from long-term engagement in knowledge building practice.

Vocabulary Growth Integral to Knowledge Building

Vocabulary knowledge is a critical aspect of literacy, being a good predictor of reading comprehension

(Anderson \& Freebody 1981; Stahl 1990) and writing quality (Astika 1993). Native English speakers learn most of their vocabulary from engagement in a variety of literacy contexts, not from direct vocabulary instruction (Nation 2001). Contextual vocabulary learning thus becomes a focal issue in vocabulary learning research (see Kuhn \& Stahl 1998 for a review). In this line of research, the concept of "context" commonly refers to a reading-based context. The task for students is to comprehend one or a few pieces of texts assigned by the teacher or researchers, which include a certain number of new words. It is expected that students can make informed guesses as to the meaning of the new words in light of available linguistic cues as well as learners' prior knowledge, including general knowledge of the world, awareness of the situation, and relevant linguistic knowledge. However, this sort of contextual learning has been found to be low in efficiency (Coady 1993; Qian 1996). The reading-based context created with a single or several readings cannot support learners' sustained, multiple encounters with the new words (Harley, Howard, \& Roberge 1996). Faced with assigned reading material, learners often lack the motivation to process the text deeply, and thus fail to learn the new words embedded in the texts (Sun \& Dong 2004), and there is limited opportunity to use the new words for authentic, communicative purposes.

Although reading context is an important source for contextual vocabulary learning, it is but one part of literacy practice in real-world listening, speaking, reading, and writing contexts. This extended network of social processes is driven, in the real world of knowledge building discourse, by authentic desire to understand the world, 
solve problems, and communicate ideas. Analysis of contextual vocabulary learning in integrated contexts of reading, writing, listening, and speaking should facilitate our understanding of how learners develop and use their vocabulary knowledge in literacy practice, and how such contexts can be created in schools to elevate vocabulary and literacy learning. In recent literature, several authors have argued for a similar shift in research focus. For example, Brown, Sagers, and LaPorte (1999) highlighted the importance of studying vocabulary learning along oral and written dialogues. Baker, Simmons, and Kameenui (1995) emphasized writing as a context for vocabulary learning, saying:

"In the context of challenging writing opportunities, it seems that not only might students be exposed to words multiple times, but the context in which such exposure occurs may facilitate deeper reflection on word meanings than occurs typically during speech or reading opportunities. ... The integration of reading and writing to promote independent vocabulary growth may apply to content area subjects. In this case, the strategic integration of reading, writing, and content area knowledge should enhance both general and content-specific vocabulary growth.” (p. 7)

The concept of contextual vocabulary learning needs to be extended beyond reading contexts to embrace integrated contexts in all curriculum domains. Knowledge building represents a pedagogical practice that supports this. As elaborated above, driven by the need to deepen understanding in various domains, students in a knowledge building classroom spontaneously find and read a large amount of textual and multimedia material. This creates a further need for participation in sustained discourse, both face-to-face and online, so students are speaking and listening in face-to-face conversations, and writing, reading, building onto, referencing, and summarizing in Knowledge Forum. The knowledge building discourse throughout serves the central goal—to improve and deepen understanding of the ideas of the community as a whole. Students are not simply responsible for advancing their 
own ideas, but the ideas of those they are interacting with, thus increasing the use of and attention to new terms and concepts. Accordingly, the knowledge building contexts afford rich opportunities for learners to observe language in real use, infer and negotiate the meanings of new words using multiple cues and cultural resources (e.g., dictionaries, subject-matter specialists). Opportunities also exist for learners to put new words into productive use in speaking and writing, gain feedback from each other and from more capable language users, including the teacher and other domain experts who might visit their class or online resources, and repeatedly encounter and use the new words in community discourse. Table 1 summarizes the characteristics presented above for vocabulary learning, contrasting knowledge building contexts with reading-based contexts as adopted in traditional contextual vocabulary learning research. The present study examines to what extent students could develop their vocabulary knowledge in the contexts of sustained knowledge building practice.

Insert Table 1 about here

\section{Measuring Productive Written Vocabulary}

Lexical knowledge is not all-or-nothing; it involves an acquisition continuum, with increasing depth of understanding over conditions of multiple and varied uses of words. Learning of a word usually progresses from receptive (e.g., being able to recognize a word in a reading) to productive knowledge (e.g., being able to use a word in writing) (Laufer 1998). The present study focused on students' growth of productive written vocabulary. This sort of vocabulary knowledge can be generally measured in three ways: direct test, evaluating learners' vocabulary use in written work based on a rating scale, and analyzing vocabulary use in learners' written work based on automated 
measures (Nation 2001). One widely used measure in the last category is lexical variation (or lexical density)

assessed by Type/Token Ratio (TTR): the number of word types (unique words) in the analyzed text divided by the number of all tokens (total words) in the analyzed text. A higher lexical variation indicates a larger size of productive vocabulary. However, lexical variation depends on the lengths of texts, and needs to hold the lengths of the texts constant to make a fair comparison (Nation 2001). Laufer and Nation (1995) proposed an alternative measure called "Lexical Frequency Profile", which provides an analysis of the percentages of word families at various frequency levels in a piece of written work, for example, the $1^{\text {st }} 1000$ and the $2^{\text {nd }} 1000$ frequent word families, and academic words. It is a measure of students' vocabulary in use. Strong correlations were found between learners' Lexical Frequency Profiles and their vocabulary size as measured by direct testing. Learners who used higher proportions of high-frequency words in their texts scored lower in the vocabulary test, and vice versa. Use of low frequency words in free writing is an indicator of richness in a learner's vocabulary (see also, Nation 2001). Lexical Frequency Profile has an advantage over other automated measures in that it does not require the length of texts to be held constant. It is thus useful for comparing vocabulary in texts of different lengths. This point is particularly important for the present study, because in Knowledge Forum, students' notes vary in length, and they typically write longer notes as they proceed with knowledge building. Therefore, in the present study, we used Lexical Frequency Profile to measure students' growth of productive written vocabulary in knowledge building discourse.

As noted above, academic vocabulary is a special type of advanced vocabulary usage in the Lexical Frequency Profile analysis, occurring across a wide range of academic texts. Coxhead (1998) created an Academic Word List, which replaced the University Word List developed by Xue and Nation (1984). The Academic Word List consists of 570 word families that are not in the most frequent 2,000 words of English, but occur at a reasonably high frequency 
in academic texts of different disciplines. These words are typical of academic discourse, which references other authors and findings (e.g., assume, establish, conclude), and works with data and ideas (e.g., analyze, assess, category). As Corson (1997) asserts, writers with academic purposes need to gain productive written control of the academic vocabulary of English in order to be recognized as a member of the academic writing community. However, these words are often difficult to process in reading and listening and to use in writing and speaking. Native English speakers mainly start using these types of words relatively late, in the adolescent years of education. As students progress to the university level, they generally show an increase in the amount of academic vocabulary in their writing (Laufer 1994). An essential way to increase the learnability of academic vocabulary is to acquaint students with the specialized areas of discourse in which such words appear, and foster their frequent and active contact with the words (Corson 1997).

Another type of specialized vocabulary is domain-specific technical terms unique to a special domain, or with particular technical uses in a domain (e.g., wave, travel, focus in optics). Grasping academic and domain-specific vocabulary in depth is essential to students' successful academic learning. Using these kinds of vocabulary in discourse is a marker of enculturation into a community of practice (Chernobilsky, Dacosta, \& Hemlo-Silver 2004). Community knowledge building across curriculum areas provides an authentic context in which students can encounter, make sense of, and repeatedly use academic and domain-specific vocabulary in the service of the goal of idea advancement. The present study explores whether young elementary students can expand their use of academic and domain-specific vocabulary through sustained knowledge building in various disciplines.

\section{This Study}

The present study examines students' vocabulary growth, productive written words in particular, as a result of their sustained knowledge building in various curriculum areas over two school years: Grade 3 and then Grade 4 . 
These primary grades are chosen partly because an important transition takes place in these two years. According to Chall's (1996) model of reading development, the transition goes from the "learning to read" stages when simple, familiar texts can be read and the alphabetic principle is acquired to the "reading to learn" stages when students begin to learn from more demanding and complex texts, with their vocabulary and knowledge expanded through reading.

Specifically, this study focuses on the following questions: (a) How much writing and reading is evident in Knowledge Forum and how did that amount change over time? (b) How did students' productive written vocabulary, gauged by Lexical Frequency Profiles, change over time? (c) How are students' Lexical Frequency Profiles and online participation related to their literacy performance on standard tests? To provide a more detailed account of students' vocabulary use and growth in their knowledge building practice, this study further analyzes a specific inquiry conducted in Grade 4, focusing on student use of domain-specific terms in written discourse and their conceptual understanding.

\section{Method}

\section{Participants and the Learning Contexts}

The participants were a class of 22 students (11 girls and 11 boys) from the Institute of Child Study Laboratory School of the University of Toronto. They were third graders (seven-to-eight-year-olds) at the beginning of this study. While most of them came from middle-class families, they represented multiple cultural and racial backgrounds and a wide range of entry capabilities. We analyzed the students' literacy engagement evident in their knowledge building work in science and social study over a two-year period - Grade 3 and then Grade 4. In the two school years, they were taught by two different teachers, both of whom had been using knowledge building pedagogy and Knowledge Forum for over two years. They investigated worms, plants, as well as geography in 
Grade 3; and living things, light, and medieval times in Grade 4, following the principles and practices for knowledge building (Scardamalia, 2002). Each inquiry initiative integrated whole-class discussions, individual and small-group work, and online discourse in Knowledge Forum. The students were encouraged to take high-level responsibility for collective, sustained inquiry processes. Instead of having the teacher design the inquiry tasks, processes, and timelines, the students took on these responsibilities as a community: to elaborate what they needed to know and identify emergent specific goals, to set forth their theories, to search for useful resources, to design experiments and collect data, and to review their progresses and focus subsequent inquiries. Knowledge Forum provided the public space in which their work was recorded, in views corresponding to their focal goals. By writing notes in these views, students shared their problems, ideas, data, and resources, and participated in extended dialogues. Figure 1 shows student discourse in the Colors of Light view in Knowledge Forum created by the students during their inquiry of light in Grade 4. The notes recorded there delve deep into issues of northern lights, rainbows, primary and secondary colors, visual spectrum, eye cones and color vision, reflection and absorption of color light, and so on. More details about the knowledge building processes in the light inquiry are provided in the Results section.

\section{Insert Figure 1 about here}

Embedded in the knowledge building processes, there were four important design elements related to language learning and use.

(a) Knowledge building discourse: Students in a knowledge building community collectively advance their knowledge through transformative knowledge building discourse, which refers to discursive practice that results in 
not only the sharing of knowledge, but also the refinement and transformation of knowledge and emergence of new ideas (Scardamalia 2002; Scardamalia \& Bereiter 1994). To engage students in knowledge building discourse in the classroom, the teachers in this study developed a design called "Knowledge Building Talk" ("KB Talk"). With students sitting in a circle, and with the teacher as an equal member of the group, the classroom conversations focused on elaborating problems and advances of understanding, with the goal of building onto each other's ideas and collectively seeking deeper understanding in a domain. Knowledge Forum supported knowledge building discourse in an online environment that was a continuation and enrichment of classroom conversations.

The teacher helped integrate online and offline discourse by referring to Knowledge Forum notes during faceto-face discussions and encouraging students to record their questions, theories, and findings from face-to-face discourse in the database.

(b) Collective responsibility for knowledge building and language use: Members in a knowledge building community share collective responsibility for communal knowledge advancement (Scardamalia 2002). This collective responsibility also extends to their language use in knowledge building discourse. When writing notes in Knowledge Forum, students were invited to elaborate their ideas and explain new terms so that others could understand their notes. For example, three students co-authored a note about mixtures of colored light: “...Green and blue make cyan, a type of blue." They gave a brief explanation for "cyan", which was a new word for them. To help other members understand the discussions taking place in a specialized view, students came up with the idea of "glossary notes", in which they gave a brief definition for each new term used in that view. They also used a strategy of "vocabulary wall", through which they shared important new terms by writing them down on the blackboard. When reading notes, students frequently provided feedback and suggestions concerning language and rhetorical issues in addition to comments on ideas. For example, in their four-month inquiry on optics in Grade 4, the students 
made 55 annotations in Knowledge Forum concerning language and rhetorical issues in peers' notes (e.g., "You missed the word..." "... does not make sense." "theroy is spelled theory").

(c) Cooperative reading of difficult texts: Constructive use of authoritative sources is a guiding principle for knowledge building communities (Scardamalia 2002). Students in this study were encouraged to find and use relevant materials to deepen their inquiry in specific domains. These materials were often above their grade level in difficulty. Students formed into small groups to cooperatively understand the material, to identify difficult words and sentences, to figure out their meanings through discussion and use of dictionaries and related materials, to produce summaries, and to generate further ideas and questions.

(d) Connecting work in the disciplines with Language Arts classes: As in all schools, Language Arts classes are conducted; these are separate from the knowledge building work, in that separate time is committed to these lessons. In the Language Arts portion the focus is on grammar, punctuation, word usage, reading and writing. What was impressive in light of the present investigation was the ways in which the teacher each year created rich connections between knowledge building in content areas and the Language Arts classes. The knowledge building work elaborated above required substantial reading, note-taking, expository writing, persuasive writing, oral communication and presentations. Because the students often shared their Knowledge Forum database with other classrooms, there was added incentive to write clear notes to help readers understand the content, and as a result greater audience awareness. Issues noticed in student writing in Knowledge Forum (e.g., spelling, word usage, grammar, writing organization) often became the focus of the Language Arts lessons. For example, in some Knowledge Forum notes, students wrote about their experiments and observations - a kind of expository writing. The Grade 4 teacher noticed that these notes often lacked details about the procedures. In the subsequent Language Arts classes, he worked with his students to improve expository writing by including specific details. There were 
also rich discussions on how to write other types of notes.

Data analyses

The primary data sources were students' online entries in Knowledge Forum during the two school years and their literacy scores on a standard test. The automated analytic tools underlying the Knowledge Forum databases (Burtis 1998) provide detailed records of each student's note writing and reading behaviors. Analyses of students' online discourse were further aided and enriched by the teachers' records of and reflections on classroom processes, aiding understanding of the dynamic interaction between online and face-to-face processes.

This longitudinal study of student vocabulary knowledge was based on their discourse data naturally generated over the two years. Because it was not possible to find a control classroom providing comparison data, we identified a set of well-established measures and benchmarks that we could compare the students' vocabulary use to and validate the impact of knowledge building practice on students' written vocabulary. These measures included:

(a) Lexical Frequency Profiles. As elaborated above, increasing use of low-frequency words indicates growth of productive written vocabulary. Existing research suggests that the change of Lexical Frequency Profiles in free writing takes a long time (Laufer 1998; Nation 2001)., with use of academic words mainly starting in the adolescent years. To examine possible changes in students' Lexical Frequency Profiles, we analyzed their Knowledge Forum notes written in each half school year, which, for convenience we call a "semester", that consists of approximately five months. Using the search function of Knowledge Forum, we pooled each student' notes for each semester. We identified and counted misspelled words, and corrected errors seemingly created by mistakes of keyboarding (e.g., missing a space between two words). A program called "Range" (Nation 2001) was then used to analyze the Lexical Frequency Profiles for each student's notes in each semester, using three wordlists: first 1,000 word families, second 1,000 word families (West 1953), and the Academic Word List (Coxhead 1998). 
(b) Grade levels of new words based on the Basic Spelling Vocabulary List. The Basic Spelling Vocabulary

List for Grade 1-5 (Graham, Harris, \& Loynachan 1993) contains 850 high frequency words that accounted for about $80 \%$ of the running words that elementary students across the US use in their writing on various themes and of different genres, with 813 words assigned to the fourth and lower grades. Although this list may not fit as precisely the vocabulary use among Canadian students, it provides a reference point for the current analysis. We used the analytic tool of Knowledge Forum to identify new written words for each student in each of the last three semesters (i.e., words that had not been used in previous semesters). Each new word was classified as either beyond or within the Grade 4 level according to the Basic Spelling Vocabulary List.

(c) Grade levels of domain-specific vocabulary based on the curriculum standard. This analysis was performed based on a sample inquiry initiative on optics conducted in the second semester of Grade 4. From The Ontario Curriculum of Science and Technology (Grade 1-8), two coders cooperatively identified 89 domain words related to light, including names of core concepts, optical devices and optical phenomena. Most of these words come from: (a) Matter and Materials (Grade 4): Materials that transmit, reflect, or absorb light; (b) Energy and Control (Grade 4): Light energy; and (c) Energy and Control (Grade 8): Optics. A few words were identified from Earth and Space Systems (Grade 1) (e.g., heat, light, sun, shadow, etc.), and Earth and Space Systems (Grade 6) (e.g., stars, solar, lunar, eclipse). We divided these words into two levels according to their first appearances in the curriculum document: 46 words at or below Grade 4, and 43 beyond Grade 4. We created a wordlist composed of these 89 words as well as their grammatical variations (e.g., absorbs, absorbed, absorbing for absorb), for a total of 180 words. Using the analytic tool of Knowledge Forum, we traced the occurrences of these words and their grammatical variations in students' notes.

Of course, the above analyses of different bands of words in student writing are only valid if students use the 
words in a meaningful way. This condition was met in the current study, because the students wrote in Knowledge Forum in order to participate in knowledge building discourse to solve authentic problems and develop ideas. When a student's note did not make sense to others, his or her peers would request clarifications and revisions. So notes in the Knowledge Forum database—-long or short—are produced in a meaningful, collaborative context.

Additionally, we collected students' scores on the Canadian Test of Basic Skills (CTBS) — a battery similar to the California Test of Basic Skills constructed to measure fundamental skills crucial to daily learning. The students took this test at the end of Grade 4. We analyzed how their scores on the literacy-related subtests (i.e., spelling, vocabulary, and reading comprehension) were correlated to their lexical frequency profiles.

To examine the relationship between vocabulary use and conceptual understanding, we conducted a detailed analysis of the same inquiry about optics conducted in Grade 4. During the inquiry, each student wrote a portfolio note in Knowledge Forum to summarize what he/she had learned about light. These portfolio notes were used as the measure of their personal knowledge gains. We divided each portfolio note into "idea units" — the smallest unit of text that conveyed a distinct idea regarding optics. Each idea unit was then coded on a four-point scale of epistemic complexity, which measures students' effort to produce not only descriptions of the material world, but also theoretical explanations and articulation of hidden mechanisms central to the nature of science (Salmon 1984). The four points were: (1) unelaborated facts, (2) elaborated facts, (3) unelaborated explanations, and (4) elaborated explanations (see Appendix 1 for details). The detailed analyses revealed students' efforts to develop an idea in writing proceeded along two dimensions: abstraction and elaboration. Two raters independently coded five students' portfolio notes, resulting in an inter-rater reliability of 0.88 (Pearson correlation). Detailed analyses of students' inquiry processes and deepening understanding were reported in Zhang, Scardamalia, Lamon, Messina, and Reeve (2007). In the present study, we calculated the correlations between the epistemic complexity level of ideas and the 
total occurrences of general, domain-specific, and academic words in the optical knowledge building discourse.

\section{Results}

\section{Note Writing and Reading in the Two School Years}

In terms of students' writing and reading behaviors in Knowledge Forum, Table 2 shows the number of notes written and percentage of notes read per student in the four semesters. On average, each student wrote 61.91 notes and read $46.50 \%$ (equivalent to a number of 566.84) of the notes of the community in the two years. Since there was considerable variation, reflected in standard deviations over the four terms, a nonparametric Friedman Test was used to examine the differences of note writing and reading behaviors across the four semesters. A significant difference was detected for the number of notes written $\left(\underline{X}^{2}=30.89, \underline{\mathrm{df}}=3, \underline{p}<.001\right)$, showing that the average number of notes created per student increased along the two years, except the first semester of Grade 4 . There was no significant difference in the percentage of notes read $(\mathrm{p}>.10)$. However, it should be realized that the actual number of notes read per student increased given that the total number of notes grew over the two years. These results suggest that the students engaged in a substantial amount of writing and reading of notes in the database over the two years. As they proceeded with knowledge building, they wrote more and read more.

Insert Table 2 about here

The students' knowledge building integrated classroom-based processes (e.g., reading, experiments, discussions) and online interactions. They designed and conducted inquiries, using all kinds of tools and resources available to improve their understanding in a domain. In their Knowledge Forum notes, the students wrote about questions they were curious about, candidate explanations to be examined, and related facts collected from 
experiments and observations, new information from reading material, responses to existing ideas as well as ways they were presented, improvements of thoughts, reflective syntheses of what they had understood and what they still needed to know, and inquiry plans to achieve their new goals. Figure 2 presents a section of student discourse on how worms sense light, which was an interesting issue emerging from their worm study in the second half of Grade 3. This example showcases the interactive, sustained, open-ended discourse through which the students identified deeper issues and refined their understanding. They acquired new words from reading material and their community discourse (e.g., MP captured the word "vibration"), invented phonetically complete spellings (e.g., "experament" for "experiment", "sence" for "sense"), and put their vocabulary into productive use to communicate and improve their ideas.

Insert Figure 2 about here

$\underline{\text { Vocabulary Use and Lexical Frequency Profiles }}$

We traced the notes written by each student in each semester, counted word tokens (total words), identified misspellings, and counted the number of correctly spelled word types (unique words) for analysis (see Table 3). The tokens $\left(\underline{X}^{2}=60.27, \underline{\mathrm{df}}=3, \underline{\mathrm{p}}<.001\right)$ and types $\left(\underline{X}^{2}=63.66, \underline{\mathrm{df}}=3, \underline{\mathrm{p}}<.001\right)$ used by each student grew rapidly along the four semesters, with sharp increases in the last semester. Interestingly, even though there was a drop in the number of notes in the first semester of Grade 4, the students still wrote more words than the previous semester, indicating that they were writing longer notes. 
Insert Table 3 about here

Table 4 reports the Lexical Frequency Profiles of students' notes written in the two years, showing the average percentages of word types from the $1^{\text {st }}$ and $2^{\text {nd }} 1,000$ word families and the Academic Word List in the four semesters. Repeated measure ANOVAs revealed significant changes in percentages of word types from the $1^{\text {st }} 1,000$ word families $\left(\underline{\mathrm{F}}(3,63)=59.66, \underline{\mathrm{p}}<.001, \underline{\underline{\eta}}^{2}=.91\right)$, the $2^{\text {nd }} 1,000$ word families $\left(\underline{\mathrm{F}}(3,63)=3.24, \underline{\mathrm{p}}<.05, \underline{\eta}^{2}=.32\right)$, and the Academic Word List $\left(\underline{F}(3,63)=30.43, \underline{p}<.001, \underline{\eta}^{2}=.86\right)$, as well as those beyond the three word lists $(\underline{F}$ $\left.(3,63)=19.86, \underline{p}<.001, \underline{\eta}^{2}=.74\right)$. The proportion of the $1^{\text {st }} 1,000$ words had a noticeable drop in Grade 4 , while those of the $2^{\text {nd }} 1,000$ words and words not included in the lists showed increases in Grade 4, with the percentage of academic words having a consistent increase over the four semesters.

Insert Table 4 about here

Students encountered new academic words in reading material they identified and their conversations with the teacher, and learned to use important academic words to communicate, justify, evaluate, and improve their ideas in the community. For example, students widely used words from the following word families: theory, design, create, debate, aspects, evidence, hypothesis, approach, challenge, clarify, identify, expand, adjust, category, conclude, cooperate, and so forth. Below is a note written by NTH—a student with an average performance in content subjects and language learning — reflecting on their inquiry of how light travels conducted in the second semester of Grade 4. Academic words are italicized. 
When we had the class debate [between light traveling in straight lines vs. in waves], I was the only student who was not on a side because my theory was light travels in waves, but the waves go in a strait line and the debate was between straight line and waves. And now we have lots of ideas from the debate and we don't know which one is right. My theory now is light travels sort of like this: Light travels in a straight line but appears to be wavy or light travels in waves but appears to be straight. That means that light has aspects of both straight lines and waves. Evidence...In our class we have seen experiments that prove both that light travels in straight lines (box with powder and shadow experiments) and wavy lines (Thomas Young experiment).

The Grade Levels of New Words

For each of the last three semesters, we identified new words that were used for the first time by a student, and analyzed the grade levels of these new words based on the Basic Spelling Vocabulary List for Grade 1-5 (Graham et al. 1993). As Figure 3 shows, each student incorporated a substantial number of new words in each semester, and did so at an increasing pace over the two years. A large proportion of the newly used words were beyond Grade 4, with a significant increase across the three semesters $\left(\underline{F}(2,42)=236.45, \underline{p}<.001, \underline{\eta}^{2}=.92\right)$.

Insert Figure 3 about here

\section{$\underline{\text { Relationships between Online Knowledge Building Discourse and Literacy Scores }}$}

We collected students' scores on three subtests of the CTBS taken at the end of Grade 4: spelling, vocabulary (word meanings), and reading comprehension. To examine how student lexical frequency profiles were related to 
their vocabulary knowledge as measured through the standard test, we computed the Pearson correlations between students' spelling and vocabulary scores and the percentages of different bands of words composing their online writing in the first and second half of the Grade 4 school year, with significant or marginally significant correlations observed (see Table 5). Higher spelling and vocabulary scores on CTBS are coincident with less frequent use of words from the first 1,000 word families, more occurrences of words from the second 1,000 word families as well as words beyond a Grade 4 level. Correlations between the use of academic words and standard test scores are less compelling (CTBS for Grade 4 does not focus on this type of vocabulary).

Insert Table 5 about here

To examine the relationships between student participation in knowledge building discourse and their literacy performance, we analyzed the correlations between students' spelling, vocabulary, and reading scores and the percent of notes read and the total number of words written in online discourse over the two school years. As Table 6 shows, significant or marginally significant correlations exist between student engagement in knowledge building discourse and their literacy performance. The deeper they engage knowledge building, the better their literacy achievement, and vice versa.

Insert Table 6 about here

$\underline{\text { Student Use of Domain-Specific Vocabulary in the Light Inquiry }}$

This analysis was performed based on an inquiry initiative on optics in the second semester of Grade 4. 
This inquiry began with a whole class discussion—known as "Knowledge Building Talk" to the students and teachers - that focused on the students' Grade 3 work. The students recalled their experiments investigating worms in their science class, and reviewed their work on how worms sense light (See Figure 2 for related notes). They showed much enthusiasm and commented that they should study light in greater detail. They talked about a number of phenomena that they were interested in: fireflies, solar panels, glow-in-the-dark materials, artificial and natural light, and mirrors and reflection. They created a "Light" view in Knowledge Forum, and started to write about their questions and theories there. Instead of organizing fixed small groups, the teacher experimented with having the whole class collaborate opportunistically to understand light and progressively identify important, related issues. New views in Knowledge Forum were created in correspondence to new major emergent goals (e.g., vision, shadows, how light travels) identified by the community through classroom conversations. On a daily basis, students were free to explore any problem from any view in the database. They all took responsibility for the overall growth of their collective knowledge space. They actively contributed ideas, raised problems, brought in resources, conducted experiments and observations. Then the ideas, problems, resources and experimental data became objects of sustained discourse in both online and offline environments. Over the four months that followed, there was selfdirected, deepening inquiry into a range of core issues in optics. In-depth analysis of students' online discourse (e.g., conceptual threads of inquiry, chains of questioning, ideas contributed, sources used, responses to each other's notes) and pre- and post-test results indicated that they had substantially improved their ideas about light, moving towards a more scientific framework and deeper understanding (see Zhang et al. 2007 for details).

In this study, we identified domain-specific words related to light from the Ontario Curriculum of Science and Technology (Grade 1-8), and looked at student use of these words in written discourse. Altogether, 120 of the 180 words (including grammatical variations), 71 of the 89 lexemes occurred in students' notes. The students 
incorporated almost all the optical vocabulary at or below Grade 4 (41 out of 46) and many of the vocabulary expected for upper grades (30 out of 43) into their online discourse. On average, each student used $43.50(\underline{\mathrm{SD}}=$ 8.63) of the 120 words for $207.08(\underline{\mathrm{SD}}=93.42)$ times.

To understand how students appropriated new domain-specific vocabulary into community discourse, we specifically traced a number of new words that had a high frequency of occurrence, thus providing a rich account of their use. For example, the word "opaque" first appeared in the Shadow view in a note authored by a student (KL), titled "What is a shadow?" He wrote:

“[New information] Shadow $=$ a darkness made when light shines on to a[n] opaque (nontransparent) thing..." (Italic added by the authors)

The scaffold label "New information" indicates that he was introducing what he learned from a reading material to the community. He picked up the term "opaque" from that material, and put a synonym in brackets to explain this new word. This note was later read by 18 of his classmates. Around the same time, several other students wrote notes about different types of materials interacting with light in the Light and Materials view. JD (a student), who had read the above note of KL, wrote a note titled: "Types of Materials", saying:

"[New information] There are three types of textures. They are transparent, translucent and opaque. Opaque means light cannot pass through, translucent means light can pass through only a bit and transparent means that light can completely pass through and you can see through that object." (Italics added by the authors)

This note was also written based on the reading of a reference, and defined the term "opaque" more clearly than KL formerly did. KL was the first to read this note, followed by nine students and the teacher. During the following two months, students continued their discussion of how different types of materials interact with light. 
They elaborated the meaning of "opaque" in more personal ways and provided specific examples. Gradually, this term was taken up in other views. For instance, in the Shadow view, MR and NTH summarized the discussions about how shadows are created: “...when light hits an opaque object it creates a shadow..." In the view called "Images in Our Eyes and in Film", YS wrote about how a camera produces an up-side-down picture of an opaque object. Altogether, the term "opaque" appeared in eight notes in the online conversations. Eventually, 21 out of the 22 students included the term in their individual portfolio notes that summarized their personal knowledge gains about light. Particularly, when they used this term, they were found to be using it meaningfully and properly.

Our analyses of other domain-specific words, for example, "concave" and "convex" (mirrors/lenses), showed a similar process. These domain-specific words, together with the concepts they represent, are central to discourse in optics. Students encountered these words in readings, talked about and with them in their online and face-to-face discourse, and used them to develop their optical understanding as they conducted related inquiry activities. Through the iterative uses of these words in various contexts, students appropriated them as productive vocabulary and used them to develop new meanings and inform new inquires. For example, when studying how light interacts with different materials, two students read a text about concave mirrors. They found interesting new information from this text, and co-authored the following note to introduce what they had learned (see Figure 4).

\section{Insert Figure 4 about here}

This note stimulated students' interests about concave mirrors. On one afternoon, the students conducted experiments to examine how flashlight worked. They noticed that the bulb was placed in a concave mirror. One of the co-authors of the above note explained why the concave mirror was needed; but most students did not 
understand. The teacher then lit a candle and placed a "paper crown" around it. The observation helped students understand that light travels in all directions from its source. They went back to examine the flashlight and realized the importance of the concave mirror in focusing the light in one direction. There were rich conversations during and following this inquiry activity, with the term of "concave mirrors" repeatedly used, better understood, and deeply connected to their evolving optical knowledge (e.g., how light travels, reflection).

The Relationship between Vocabulary Use and Idea Complexity

This analysis was also conducted for the inquiry of light. Using a four-point scale (1- unelaborated facts, 2elaborated facts, 3-unelaborated explanations, and 4-elaborated explanations), we rated the epistemic complexity of students' ideas about light summarized in their personal portfolio notes. Then we computed the Pearson correlations between the total occurrences of general, domain-specific, and academic vocabulary in the optical knowledge building discourse and the epistemic complexity level of understanding achieved through inquiry. The complexity level of students' ideas was significantly correlated with the number of total words (Pearson $\underline{r}=.49, \underline{p}<.05$ ) as well as the total occurrences of domain-specific words $($ Pearson $\underline{r}=.54, \underline{p}<.05)$ and academic words $($ Pearson $\underline{r}=.55, \underline{p}$ $<.01)$ in students' notes written for the optical inquiry.

\section{Discussion}

To examine the impact of extended, collaborative knowledge building on students' vocabulary growth, this study traced students' vocabulary use in online knowledge building discourse over two school years, and investigated the relationships between vocabulary use and the level of understanding achieved through inquiry. Our vocabulary analysis was based on students' online writings spontaneously generated during the knowledge building process, therefore reflecting their productive vocabulary (Laufer \& Paribakht 1998).

Student Engagement in Writing and Reading 
The first research question relates to the amount of writing and reading in the course of knowledge building.

Over the two school years, each student wrote an average of 61.90 notes consisting of 3,867.55 tokens (total words) and 715.45 types (unique words) (see Table 2 and 3). Each student read nearly a half of the total notes of the community. For a Grade 3/4 student, this result represents a substantial amount of reading and writing work outside of the Language Arts class. More importantly, the numbers of notes written and read, especially the numbers of word tokens and types in the notes, increased rapidly over the two years, as the students were engaged into knowledge building practice. The growth of language competency and knowledge building practice appeared to be mutually supportive.

Changes in Lexical Frequency Profiles in Relation to Literacy Performance

The second and third research question focused on changes in Lexical Frequency Profiles in relation to student literacy performances on a standard test. Existing research suggests that the change of Lexical Frequency Profiles in free writing takes a long time. It is not easy to bring receptive words into productive use, particularly for relatively low frequency words (Laufer 1998; Nation 2001). The present study demonstrated a noticeable change of students' Lexical Frequency Profiles. As they proceeded with the knowledge building discourse, the proportion of the $1^{\text {st }}$ 1,000 frequent words dropped, and those of the $2^{\text {nd }} 1,000$ words, academic words, and words beyond the lists increased (see Table 4). According to Laufer and Nation (1995), these changes should be considered strong indicators of students' growth in productive written vocabulary. Additionally, the analyses of students' new words in each semester (Figure 3) demonstrated that each student on average incorporated a substantial and increasing number of new words into the discourse, a large percentage of which were beyond a Grade 4 level according to the Basic Spelling Vocabulary List of elementary students (Graham et al., 1993). There were noticeable correlations between the above automated measures of vocabulary and the standard test, showing that the increasing use of more 
advanced words and decreasing use of the first 1,000 words are associated with higher vocabulary and spelling scores. The deeper students were engaged in knowledge building work, the better their literacy gains (Table 5 and 6). The extended knowledge building practice provides an effective means for enlarging students' vocabulary size, deepening their vocabulary knowledge, and bringing more words into productive use. It can help learners develop their vocabulary knowledge as well as motivation to use the new words, which is an important factor affecting productive vocabulary growth (Nation 2001).

With regard to academic words, the analysis of Lexical Frequency Profiles revealed a significant increase for the percentage of words from the Academic Word List from 1.61\% to $4.15 \%$. The knowledge building practice brings about rich opportunities for developing students' academic vocabulary, which previous research suggests is hard to learn and use, and mainly developed through secondary and higher education (Corson 1997). Driven by work in a knowledge building community, students found and read a large number of academic texts, including those for a grade level higher than their own. In these readings, they frequently encountered academic words, some of which were later used in writing in Knowledge Forum. More importantly, the knowledge building pedagogy encourages students to participate in sustained knowledge building discourse, in both oral and written formats, that mirrors the authentic academic discourse characteristic of research communities. Students learned academic words in order to communicate, justify, evaluate, and improve their ideas in the community. By engaging in disciplinary conversations to which academic vocabulary was an essential part, they received more frequent contact with the morphological and semantic features of these words and developed their readiness to put the words to work (Corson 1997).

Student Vocabulary Use and Conceptual Understanding in the Light Inquiry

The analysis of domain-specific vocabulary in the inquiry of light indicated that students included almost all 
the specialized vocabulary expected for Grade 4 or below, as well as about 3/4 of those expected for upper grades.

The analyses of the word "opaque" and other terms in student writing suggested an incremental and interactive

process of vocabulary learning through knowledge building. The students encountered the new terms when reading

reference material about focal inquiry themes. They tried to figure out the meanings of these terms, and wrote notes

to introduce these terms and the new information they conveyed to the community. The terms were then elaborated

based on further reading and discussions, and used to solve problems and deepen understanding in related inquiries

(e.g., shadows, cameras). Through extensive online and face-to-face interactions, the new terms were diffused to

community members and became part of their productive written vocabulary. This process coincides with what

Chernobilsky and colleagues (2004) observed in a problem-based course, in which undergraduate students

progressively appropriated professional vocabulary through social interactions. These students progressed from

unelaborated use of terms, to meaning development and elaboration, and eventually using the terms and concepts as

conceptual tools for problem solving. The results of the present study suggest that young students could similarly

benefit from knowledge building interactions and develop domain-specific vocabulary. Knowledge building

integrates work in any domain with multiple modes of literacy in the service of cooperative problem solving and

idea advancement. It affords rich opportunities for learners to be exposed to various contexts of word use, learn new

domain-specific words from authoritative sources (e.g. reference materials, teachers) and peers, collaboratively

understand these terms, and use them in meaningful ways to share and improve ideas and address deep issues in a

domain.

Students' continual pursuit of deeper explanations coincided with their growing use of vocabulary and level of

understanding. Language and cognition interact with one another in a dialectical fashion (Salomon 1993; Vygotsky

1986). The expansion of inquiry and the development of ideas drive students to find increasingly appropriate terms 
to frame and communicate their ideas; in parallel, the use of new and more sophisticated words, especially domainspecific and academic words, helps transform their ideas toward higher levels of elaboration, abstraction, and integration, enhancing high-level writing and literacy (Applebee et al. 2003; Bereiter \& Scardamalia 1987b).

\section{$\underline{\text { Reflections on Classroom Practices }}$}

Overall, the results suggest the positive effects of long-term knowledge building practice on the development of productive written vocabulary, as well as the transformative role of language in collaborative inquiry of content areas. As elaborated in the Methods section, a number of specific designs might have contributed to students' knowledge building and vocabulary growth. These included: sustained engagement in knowledge building discourse mediated by oral and written language; cooperative reading of difficult texts driven by problems of understanding; taking collective responsibility for both deepening understanding and effective discourse in a community; and building connections between work in content areas and Language Arts classes.

The knowledge building discourse focuses on authentic problem solving (Nystrand 1997) and provides an engaging, rich, and interactive context for spontaneous and deep vocabulary learning. The idea-focused, progressive discourse brings students into contact with a variety of knowledge resources that involve new vocabulary use. It promotes multiple encounters with new terms during listening and reading, active use of new words in written and oral discourse, and reciprocal feedback regarding vocabulary use among participants.

By collaboratively making sense of material, which illustrates the use of terms in a system of academic meaning-making (Corson 1997), students acquire new academic, technical, as well as general vocabulary and deepen their knowledge about existing terms. These terms are subsequently used in extended knowledge building discourse to help represent, process, communicate, and develop deep ideas.

By sharing collective responsibility for language use in community discourse, students maintain the social 
norm of sharing ideas and contributing to collective understanding, and provide mutual support to each other's

language use and reflection. They write clear content and explain new terms in their notes so others can understand their ideas, write glossary notes to highlight and define important terms, request for clarification when they find a note lacks information, and provide feedback on note writing. Their mutual engagement helps to bootstrap the discourse of the community as a whole as well as the language performance of each individual. In their collaborative discourse, their "saying" becomes "what they said", providing an object for collaborative reflection. Through saying and reflecting on what was said, new linguistic knowledge is constructed (Swain 2000).

Students constantly shift between reading of professional material, knowledge building talks, and written discourses in the online environment, maintaining a dynamic flow between different modes of literacy practice. In the classroom and in Knowledge Forum, they repeatedly talk about knowledge gained from professional texts, with words that were unfamiliar to students in form and meaning (Olson 1997); they summarize important ideas that have emerged from classroom conversations and written dialogues in Knowledge Forum. They then refer back to their Knowledge Forum notes or project selected notes onto a screen to support their classroom conversations. The integration of different modes, involving both language input and output, facilitates deep processing of language and knowledge. It is through this integrated process that language use and language learning co-occur, with language use for meaning-making mediating language learning.

\section{Conclusions}

This study investigated students' literacy engagement during their sustained, collaborative knowledge building in various subject areas. It revealed significant vocabulary growth associated with sustained knowledge building practice. Student engagement in significant and sustained knowledge building was reflected in increasing numbers of notes written and read in Knowledge Forum. The analysis of Lexical Frequency Profiles of the online discourse 
indicated a significant growth of students' productive written vocabulary, including academic words. Each student on average incorporated a substantial and increasing number of new words into their discourse, a large percentage of which were beyond the level expected for Grade 4. Students' online discourse on optics incorporated almost all the domain-specific terms at and below students' grade as well as most of those expected for upper grades, as reflected in the curriculum guidelines. Students' use of general, domain-specific, and academic words were closely correlated to the level of understanding they achieved through knowledge building, as reflected in the qualitative evaluation of their portfolio notes. There were compelling correlations between student engagement in knowledge building and their literacy gains on the standard test.

These results provide preliminary evidence that deep, sustained disciplinary knowledge building results in substantial gains in literacy (Scardamalia, 2003). This finding could have a significant impact on school curriculum, and lessen the time committed to language skills alone, devoid of substantial work with ideas. By integrating literacy practices with knowledge building, the two teachers in this study reportedly spent less time on Language Arts as an isolated curricular activity, with better results for students' language arts.

In a follow-up analysis of the same dataset, we examined whether knowledge building can engage both boys and girls in collaborative inquiry and develop their vocabulary, with positive findings (Sun, Zhang, Scardamalia, in press). To better understand the complex picture of student literacy engagement in knowledge building, we will further examine vocabulary growth in relation to other literacy indicators such as syntactic complexity, writing organization, and dialogic contribution; and extend analyses to classes with more diverse student populations and greater literacy challenges.

\section{Acknowledgements}

This research was funded by an "Initiative on the New Economy" Grant from the Social Sciences and 
Humanities Research Council of Canada (512-2002-1016). An earlier version of this article was presented at the Annual Meeting of the American Educational Research Association, 2006, San Francisco, CA. We are particularly thankful to the students, teachers, and principal of the Institute of Child Study, University of Toronto, for the insights, accomplishments and research opportunities enabled by their work.

\section{References}

Anderson, R. \& Freebody, P. (1983). Reading comprehension and the assessment and acquisition of word knowledge. Advances in Reading/Language Research, $\underline{2}, 231-256$.

Applebee, A.N. (1981). Writing in the secondary school. Urbana, IL: National Council of Teachers of English.

Applebee, A. N. (1996). Curriculum as conversation: Transforming traditions of teaching and learning. Chicago, IL: University of Chicago Press.

Applebee, A. N., \& Langer, J.A. (2006). The state of writing instruction in America's schools: What existing data tell us. Research report of the Center on English Learning and Achievement, University at Albany.

Applebee, A. N., Langer, J.A., Nystrand, M., \& Gamoran A. (2003). Discussion-based approaches to developing understanding. American Educational Research Journal, 40 (3), 685-730.

Astika, G.G. (1993). Analytical assessment of foreign students' writing. RELC Journal, 24, 61-72.

Baker, S.K., Simmons, D.C., \& Kameenui, E.J. (1995). Vocabulary acquisition: Curricular and instructional implications for diverse learners. A technical report to the U.S. Office of Special Education Programs. National Center to Improve the Tools of Educators. University of Oregon.

Bakhtin, M. M. (1981). The dialogic imagination: Four essays (C. Emerson \& M. Holquist, Trans.). Austin, TX: University of Texas Press.

Bereiter, C. (2002). Education and mind in the knowledge age. Mahwah, NJ: Erlbaum. 
Bereiter, C. \& Scardamalia, M. (1987a). An attainable vision of high literacy: Approaches to teaching higher-order skills in reading and writing. Curriculum Inquiry, 17(1), 9-30.

Bereiter, C. \& Scardamalia, M. (1987b). The psychology of written composition. Hillsdale, NJ: Erlbaum.

Bransford, J.D., Brown, A. L., \& Cocking, R. R. (Eds.). (2000). How people learn: Brain, mind, experience, and school (expanded ed.). Washington, D.C.: National Academy Press.

Brown, C., Sagers, S.L. and LaPorte, C. (1999). Incidental vocabulary acquisition from oral and written dialogue journals. Studies in Second Language Acquisition, 21, 259-283.

Burtis, J. (1998). Analytic Toolkit report. Toronto, ON: Ontario Institute for Studies in Education of the University of Toronto.

Cantoni-Harvey, G. (1987). Content-area language instruction: Approaches and strategies. Reading, MA: AddisonWesley.

Chall, J. S. (1996). Stages of reading development (2nd ed.). Fort Worth, TX: Harcourt Brace.

Chernobilsky, E., DaCosta, M. C., \& Hmelo-Silver, C. E. (2004). Learning to talk the educational psychology talk through a problem-based course. Instructional Science, $\underline{32}$ (4), 319-356.

Coady, J. (1993). Research on ESL /EFL vocabulary acquisition: Putting it in context. In T. Huckin, M. Haynes, \& J. Coady (Eds.), Second language reading and vocabulary learning (p. 3-23). Norwood, NJ: Ablex Publishing.

Connolly, P., \& Vilardi, T. (1989). Writing to learn mathematics and science. New York: Teachers College Press.

Corson, D.J. (1997). The learning and use of academic English words. Language Learning, 47, 671-718.

Coxhead, A. (1998). An academic word list. Occasional publication Number 18, LALS, Victoria University of Wellington, New Zealand.

Graham, S., Harris, K., \& Loynachan, C. (1993). The basic spelling vocabulary list. Journal of Educational 
Research, $\underline{86}, 363-368$.

Guthrie, J. T., Wigfield, A., \& Perencevich, K. C. (Ed.). (2004). Motivating reading comprehension: ConceptOriented Reading Instruction. Mahwah, NJ: Erlbaum.

Harley, B., Howard, J., \& Roberge, B. (1996). Teaching vocabulary: an exploratory study of direct techniques. Canadian Modern Language Review, $\underline{53}$, 281-304.

Kuhn, M. R. \& Stahl, S. A. (1998). Teaching children to learn word meanings from context: A synthesis and some questions. Journal of Literacy Research, $\underline{30}(1), 119-138$.

Lamon, M., Secules, T., Petrosino, A. J., Hackett, R., Bransford, J. D., and Goldman, S. R. (1996). Schools for thought: Overview of the international project and lessons learned from one of the sites. In L. Schauble \& R. Glaser (Eds.), Contributions of instructional innovation to understanding learning (pp.243-288). Hillsdale, NJ: Lawrence Erlbaum.

Lamy, M. N., \& Goodfellow, R. (1999). "Reflective conversation" in the virtual language classroom. Language Learning \& Technology, 22(2), 43-61.

Laufer, B. \& Nation, P. (1995). Vocabulary size and use: Lexical richness in L2 written production. Applied Linguistics, 16, 307-322.

Laufer, B. \& Paribakht, T. S. (1998). The relationship between passive and active vocabularies: Effects of language learning context. Language Learning, $\underline{48(3), 365-391 . ~}$

Laufer, B. (1994). The lexical profile of second language writing: Does it change over time? RELC Journal, 25, 2133.

Laufer, B. (1998). The development of passive and active vocabulary in a second language: Same or different. Applied Linguistics, $19,255-271$. 
Lehrer, R., Carpenter, S., Schauble, L., \& Putz, A. (2000). Designing classrooms that support inquiry. In J. Minstrell \& E. V. Zee (Eds.), Inquiring into inquiry learning and teaching in science (pp. 80-99). Washington, D.C.: American Association for the Advancement of Science.

Nation, I.S.P. (2001). Learning vocabulary in another language. Cambridge, UK: Cambridge University Press.

National Research Council (NRC) (2000). Inquiry and the national science education standards: A guide for teaching and learning. Washington, DC: National Academy Press.

Nystrand, M. (1997). Opening dialogue: Understanding the dynamics of language and learning in the English classroom. New York: Teachers College Press.

Olson, D.R. (1997). Talking about text and culture of literacy. In B. Davis \& D. Corson (Eds.), Oral discourse and education (pp.1-9). Boston, MA: Kluwer.

Paavola, S., \& Hakkarainen, K. (2005). The knowledge creation metaphor - An emergent epistemological approach to learning. Science \& Education, $\underline{14}$, 535-557.

Qian, D. D. (1996). ESL vocabulary acquisition: contexualization and decontextualization. Canadian Modern Language Review, 53, 120-142.

Salmon, W. C. (1984). Scientific explanations and the causal structure of the world. Princeton, NJ: Princeton University Press.

Salomon, G. (1993). No distribution without individuals' cognition. In: G. Salomon (Eds.), Distributed cognitions: Psychological and educational considerations (pp. 188-228). NY: Cambridge University Press.

Scardamalia, M. (2002). Collective cognitive responsibility for the advancement of knowledge. In B. Smith (Eds.) Liberal education in a knowledge society (pp. 67-98). Chicago, IL: Open Court. Scardamalia, M. (2003). Crossing the digital divide: Literacy as by-product of knowledge building. Journal of 
Distance Education, 17 (Suppl. 3, Learning Technology Innovation in Canada), 78-81.

Scardamalia, M. (2004). CSILE/Knowledge Forum ${ }^{\circledR}$. In A. Kovalchick, \& K. Dawson (Eds.), Education and technology: An encyclopedia (pp. 183-192). Santa Barbara, CA: ABC-CLIO, Inc.

Scardamalia, M., \& Bereiter, C. (1994). Computer support for knowledge building communities. Journal of the Learning Sciences, $\underline{3}, 265-283$.

Scardamalia, M., Bereiter, C., Brett, C., Burtis, P.J., Calhoun, C., \& Smith Lea, N. (1992). Educational applications of a networked communal database. Interactive Learning Environments, 2 (1), 45-71.

Scardamalia, M., Bereiter, C., Hewitt, J., \& Webb, J. (1996). Constructive learning from texts in biology. In K. Fischer \& M. Kirby (Eds.), Relations and biology learning: The acquisition and use of knowledge structures in biology (pp. 44-64). Berlin: Springer-Verlag.

Stahl, S.A. (1990). Beyond the instrumentalist hypothesis: Some relationships between work meanings and comprehension. Technical report No. 505 of the Center for the Study of Reading, University of Illinois at Urbana-Champaign.

Sun, Y. \& Dong, Q. (2004) Effects of learning support on children's English vocabulary learning in multimedia context. Computer Assisted Language Learning, 17(2), 131-147

Sun, Y., Zhang, J., \& Scardamalia, M. (in press). Developing deep understanding and literacy while addressing a gender-based literacy gap. Canadian Journal of Learning and Technology.

Swain, M. (2000). The output hypothesis and beyond: mediating acquisition through collaborative dialogue. In J. Lantolf (Eds.), Sociocultural theory and second language learning (pp. 97-114). Oxford University Press.

Vygotsky, L.S. (1986). Thought and language (Kozulin, A., Trans.). Cambridge, MA: MIT Press. (Original work was published in 1934). 
Warschauer, M. (2000). Online learning in second language classrooms: An ethnographic study. In M. Warschauer \& R. Kern (Eds.), Network-based language teaching: Concepts and practice. New York, NY: Cambridge University Press.

Warschauer, M. (2007). Technology and writing. In J. Cummins and C. Davison \& (Eds.), International Handbook of English Language Teaching (pp. 907-918). New York, NY: Springer.

West, M. (1953). A general service list of English words. London, UK: Longman, Green \& Co.

Xue, G. \& Nation, P. (1996). A university word list. Language Learning and Communication, $\underline{3}, 215-229$.

Zhang, J., Scardamalia, M., Lamon, M., Messina, R., \& Reeve, R. (2007). Socio-cognitive dynamics of knowledge building in the work of nine- and ten-year-olds. Educational Technology Research and Development, 55(2), $117-145$.

Zhang, J., \& Sun, Y. (2005). Constructive learning: An integrated view from the learning sciences. Shanghai, China: Shanghai Education Publishing House.

Zhao, Y., Englert, C.S., Chen, J., Jones, S.C., \& Ferdig, R.E. (2000). The development of a Web-based literacy learning environment: A dialogue between innovation and established practices. Journal of Research on Computing in Education, $\underline{32}(4), 435-454$. 


\section{Appendix 1:}

Rating of Students' Ideas in Their Portfolio Notes.

Categories and defining features $\quad$ Examples

(1) Unelaborated facts: Description of The law of reflection is the angel of incidence equals the angel of terms, phenomena, or experiences reflection.

without elaboration.

(2) Elaborated facts: Elaboration of terms, phenomena, or experiences.

(3) Unelaborated explanations:

Reasons, relationships, or mechanisms

mentioned without elaboration.

(4) Elaborated explanations: Reasons, relationships, or mechanisms

elaborated.
The law of reflection is that if you shine light at a 90 degree angle it will be reflected as a 90 degree angle. [T]he light ray that goes to the flat mirror is called the incident ray and the ray that bounces off is called reflected ray.

This is how a shadow is made: a shadow is made when light hits an object.

A shadow is the darkness on the other side of an opaque object, which is non-transparent. When a light shines on an opaque object, the light can't get around it so there is only darkness, which is a shadow. 


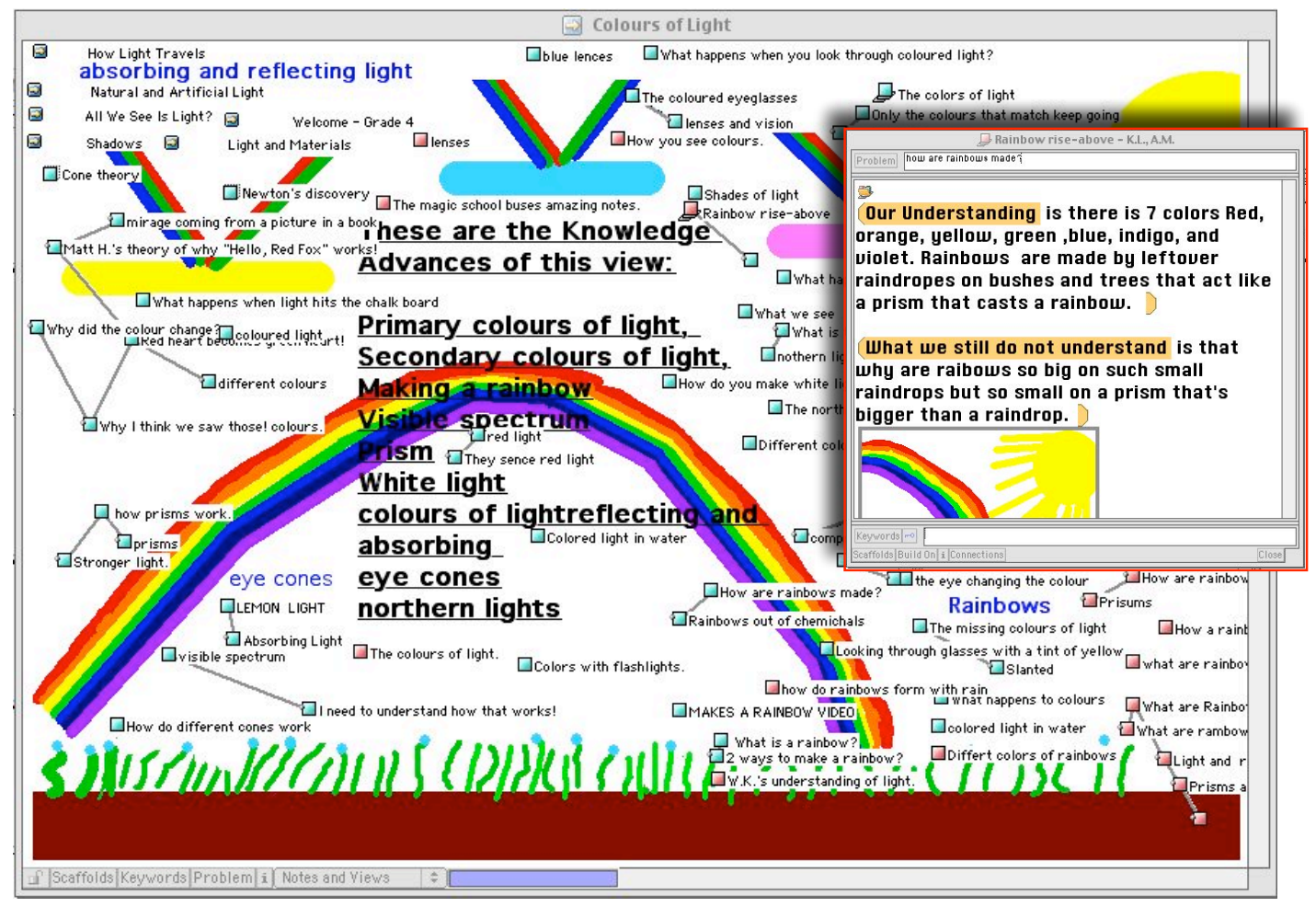

Figure 1. Knowledge building discourse in the Colors of Light view. Each square icon represents a note, and a line

linking two square icons represents a build-on. The opened note is a rise-above note two students created to

summarize what the class had learned and what they still needed to understand about rainbows. The discourse took

students deep into various theories and problems of understanding. To represent the evolving goals, students created

subsections within the view: absorbing and reflecting light, northern lights, eye cones, and rainbows. Near the end of

this inquiry, the students had a talk to collectively review advances in this view, and highlighted the advances in the

view background. 


\section{Worms sense light, by MP}

Problem: Worms sense light.

The survival group did a[n] exper[i]ment on worms sensing light. We know worms sense light because we shin[e]d light on worms and they went under the black paper.

Keywords: worms

\section{Worms sense light, by AS}

Problem: Can worms sense light?

My theory is that worms hate the light. I need to understand if it's because it hurts their eyes. Worms like it dark and moist.

\section{Eyes, by MP}

Problem: Can worms sense light?

Worms don't have eyes.

Keywords: worms

\section{Can worms sen[s]e light, by VE}

Problem: Can worms sense light?

They can not see or smell but they can sen[s]e light.

(untitled), by NTH

Problem: Can worms sense light?

How?

Skin, by MP

Problem: Skin

A worm's skin can feel vibrations.

\section{Red light, by NTH}

I just found out that earthworms can sen[s]e light but not red light. Scientists may use red light to study worms so the worms won't s[qu]iggle. And fishermen may use red light to look for worms in the dark, but they be careful not to make to[o] much noise. 


\section{Red light white light, by RB}

Problem: red bin white light

NTH was looking at the worms when she opened the red bin and the worms went down to the bottom. We think it's because the white light was shining on the worms.

Figure 2. A section of students' online discourse on how worms sense light in the second semester of Grade 3. An

indented note was a build-on note responding to the preceding note. Knowledge Forum encourages students to include a title, a problem statement, and one or more keywords in a note, although these features are optional. 


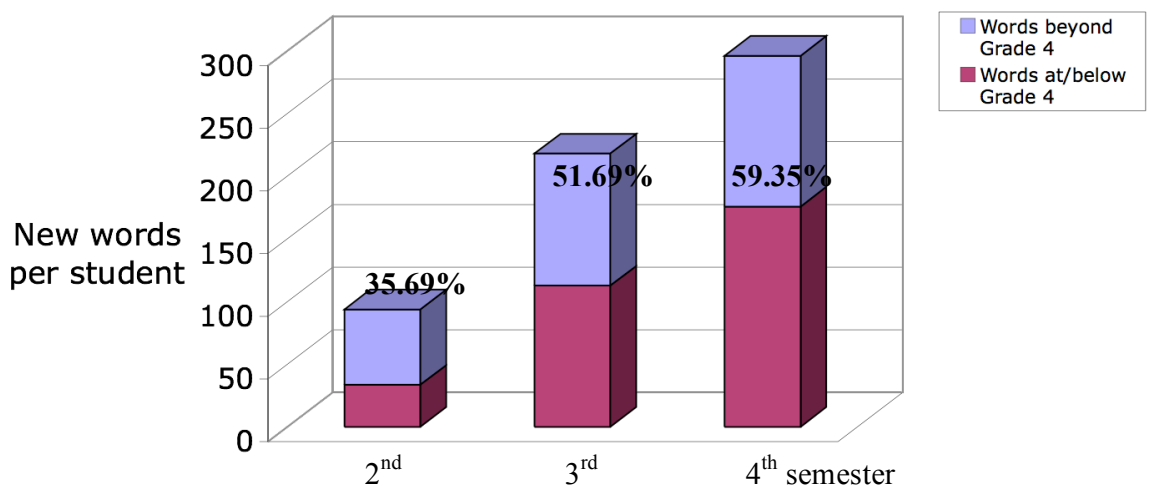

Figure 3. The number and grade level of new words used by each student in each of the last three semesters. New words of a student are defined as words he/she newly included in online writing and that had not ever been used by him/her in the previous semester(s). The percentages in this graph show the proportions of new words beyond Grade 4, according to the Basic Spelling Vocabulary List for Grade 1-5 (Graham et al., 1993). 


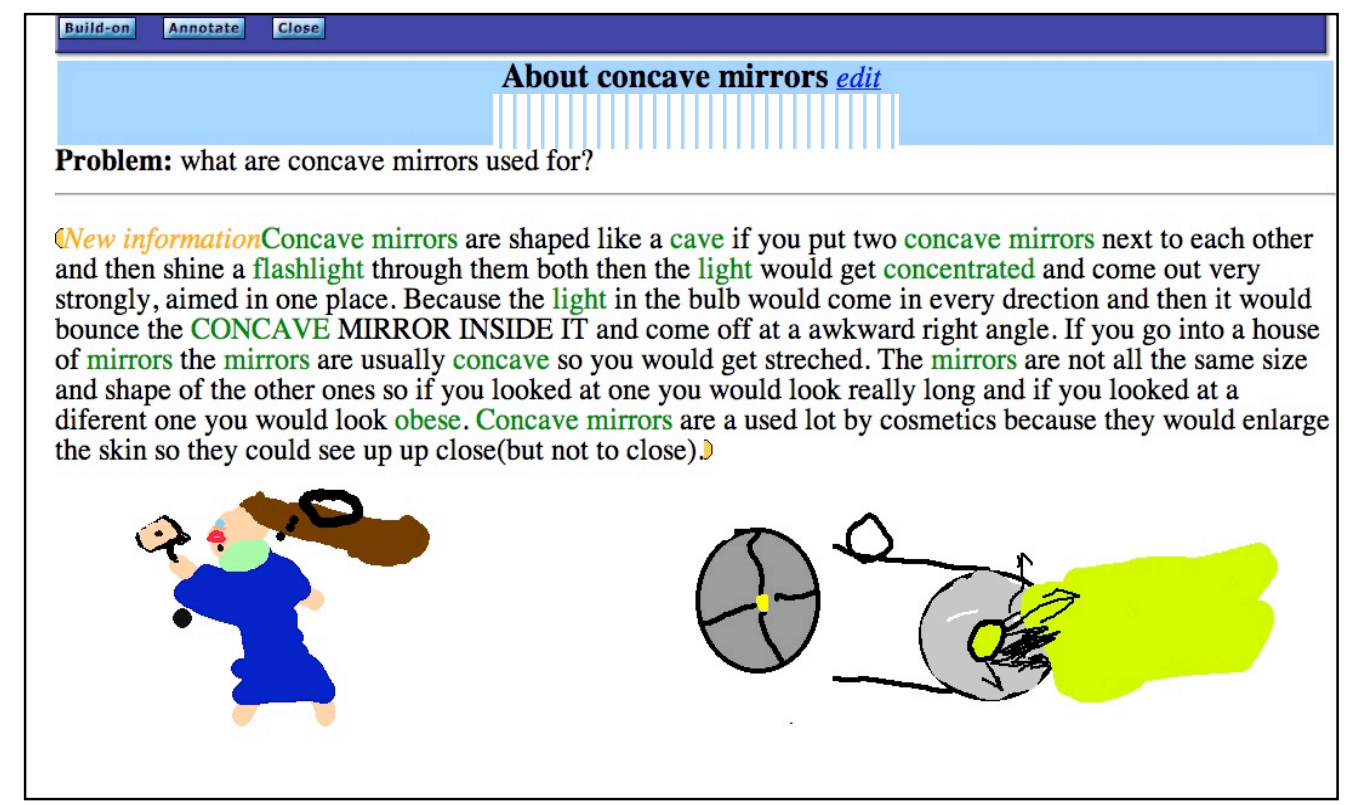

Figure 3. A note co-authored by two students in their light inquiry in Grade 4 . The authors' names have been

masked due to research compliance requirement. 
Table 1

Contrast Knowledge Building Contexts with Reading-Based Contexts in Contextual Vocabulary Learning Research.

\begin{tabular}{|c|c|c|}
\hline & Reading-Based Contexts & Knowledge Building Contexts \\
\hline Goal & Comprehension of texts & Generating and improving ideas \\
\hline Input & $\begin{array}{l}\text { One or several texts identified by } \\
\text { the teacher or researchers. }\end{array}$ & $\begin{array}{l}\text { Texts and multimedia materials identified by students on a } \\
\text { need-to-know basis; Sustained online discourse that includes } \\
\text { texts and multimedia elements created by the community; } \\
\text { Conversation among students, the teacher, and other } \\
\text { knowledgeable adults or "virtual visitors" to their knowledge } \\
\text { spaces. }\end{array}$ \\
\hline Output & $\begin{array}{l}\text { Answering questions based on } \\
\text { the content of the texts, or no } \\
\text { visible output at all. }\end{array}$ & $\begin{array}{l}\text { Summarizing and sharing readings, generating questions, and } \\
\text { contributing and refining ideas in online and face-to-face } \\
\text { discourse; Providing checks of information and new } \\
\text { information in a variety of class contexts. }\end{array}$ \\
\hline $\begin{array}{l}\text { Interactions and } \\
\text { feedback }\end{array}$ & $\begin{array}{l}\text { Individual comprehension } \\
\text { checks; inferring meaning of } \\
\text { new words using text-based } \\
\text { clues, usually with no explicit } \\
\text { feedback. }\end{array}$ & $\begin{array}{l}\text { Cooperative efforts to understand difficult texts and improve } \\
\text { ideas, with feedback to the process resulting from the ability } \\
\text { to read and compare the work of all participants, and further } \\
\text { aided by reactions from the teacher and peers. }\end{array}$ \\
\hline
\end{tabular}


Table 2

Note Writing and Reading Behaviors in the Two School Years.

\begin{tabular}{|c|c|c|c|c|c|}
\hline & \multicolumn{2}{|c|}{ Grade 3} & \multicolumn{2}{|c|}{ Grade 4} & \multirow[t]{2}{*}{ Total } \\
\hline & The $1^{\text {st }}$ semester & The $2^{\text {nd }}$ semester & The $1^{\text {st }}$ semester & The $2^{\text {nd }}$ semester & \\
\hline & Mean ( $\underline{\mathrm{SD}})$ & Mean ( $\underline{\mathrm{SD}})$ & Mean ( $\underline{\mathrm{SD}})$ & Mean ( $\underline{\mathrm{SD}})$ & Mean ( $\underline{\mathrm{SD}})$ \\
\hline$\#$ of notes written & $11.27(7.55)$ & $15.95(9.47)$ & $12.91(7.06)$ & $21.77(7.74)$ & $61.91(27.64)$ \\
\hline$\%$ of notes read & $43.40 \%(13.88 \%)$ & $38.90 \%(19.53 \%)$ & $47.20 \%(13.85 \%)$ & $42.60 \%(17.75 \%)$ & $46.50 \%(14.10 \%)$ \\
\hline
\end{tabular}


Table 3

Tokens (Total Words) and Types (Unique Words) in Each Student's Notes in the Two School Years.

\begin{tabular}{|c|c|c|c|c|c|}
\hline & \multicolumn{2}{|c|}{ Grade 3} & \multicolumn{2}{|c|}{ Grade 4} & \multirow[t]{2}{*}{ Total } \\
\hline & The $1^{\text {st }}$ semester & The $2^{\text {nd }}$ semester & The $1^{\text {st }}$ semester & The $2^{\text {nd }}$ semester & \\
\hline & Mean $(\underline{\mathrm{SD}})$ & Mean $(\underline{\mathrm{SD}})$ & Mean $(\underline{\mathrm{SD}})$ & Mean $(\underline{\mathrm{SD}})$ & Mean ( $\underline{\mathrm{SD}})$ \\
\hline Total tokens & $246.45(175.67)$ & $300.41(235.63)$ & $842.18(462.33)$ & $1841.64(944.33)$ & $3230.68(1725.48)$ \\
\hline Total types ${ }^{\text {a }}$ & $107.41(48.90)$ & $213.09(86.52)$ & $291.27(98.34)$ & $439.14(121.25)$ & $715.45(193.05)$ \\
\hline
\end{tabular}

Note. ${ }^{a}$ Misspellings were excluded when counting total word types. The numbers of types of the four semesters do not add up to the total types of the two years because some types were repeated across the semesters. 
Table 4

Comparison of Lexical Frequency Profiles Based on Counts of Word Types.

\begin{tabular}{ccccc}
\hline & \multicolumn{2}{c}{ Grade 3} & \multicolumn{2}{c}{ Grade 4} \\
\hline & The $1^{\text {st }}$ semester & The $2^{\text {nd }}$ semester & The $1^{\text {st }}$ semester & The $2^{\text {nd }}$ semester \\
& Mean (SD) & Mean (SD) & Mean (SD) & Mean (SD) \\
\hline 1st 1,000 words & $73.33 \%(4.09 \%)$ & $76.43 \%(4.90 \%)$ & $67.98 \%(3.30 \%)$ & $66.02 \%(2.35 \%)$ \\
$2^{\text {nd }} 1,000$ words & $9.93 \%(2.53 \%)$ & $9.13 \%(2.80 \%)$ & $9.90 \%(1.78 \%)$ & $10.89 \%(1.48 \%)$ \\
Academic words & $1.61 \%(0.83 \%)$ & $1.77 \%(1.07 \%)$ & $2.75 \%(1.27 \%)$ & $4.15 \%(0.90 \%)$ \\
Other $^{a}$ & $24.01 \%(6.33 \%)$ & $21.34 \%(8.03 \%)$ & $30.39 \%(7.57 \%)$ & $29.55 \%(5.79 \%)$ \\
\hline
\end{tabular}

Note. $^{a}$ This category included low frequency words that are not in the above three word lists and a small number of correctly spelled names and abbreviations. Misspellings were excluded. 


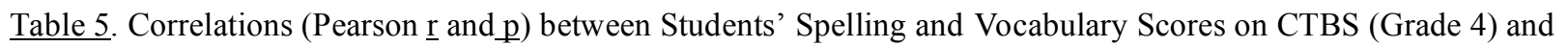
the Lexical Frequency Profiles of Their Online Discourse in the First and Second Half of Grade 4.

\begin{tabular}{|c|c|c|c|c|c|c|c|c|}
\hline & \multicolumn{4}{|c|}{ First Half School Year } & \multicolumn{4}{|c|}{ Second Half School Year } \\
\hline & $\%$ of $1 \mathrm{st}$ & $\%$ of 2 nd & $\%$ of & \# of words & $\%$ of $1 \mathrm{st}$ & $\%$ of $2 n d$ & $\%$ of & \# of words \\
\hline & 1,000 & 1,000 & academic & beyond Grade & 1,000 & 1,000 & academic & beyond Grade \\
\hline & words & words & words & 4 & words & words & words & 4 \\
\hline Spelling & $-.51 *$ & .42 & $.44^{*}$ & .38 & $-.45^{*}$ & $.43^{*}$ & .23 & $.43 *$ \\
\hline score & $(.015)$ & $(.054)$ & $(.042)$ & $(.086)$ & $(.034)$ & $(.047)$ & $(.307)$ & $(.049)$ \\
\hline Vocabulary & -.27 & .36 & .03 & .40 & $-.52 *$ & .38 & .01 & $.58 * *$ \\
\hline score & $(.226)$ & (.099) & $(.904)$ & $(.063)$ & $(.012)$ & $(.083)$ & $(.979)$ & $(.005)$ \\
\hline
\end{tabular}

$* \underline{\mathrm{p}}<.05 ; * * \underline{\mathrm{p}}<.01$ (two-tailed). 
Table 6. Correlations (Pearson $\underline{\mathrm{r}}$ and $\underline{\mathrm{p}}$ ) between Students' Literacy Scores on CTBS (Grade 4) and Their Participation in Online Knowledge Building Discourse over the Two School Years.

\begin{tabular}{lrr}
\hline & \% of notes read & \# of words written \\
\hline Spelling score & .39 & $.49^{*}$ \\
& $(.074)$ & $(.021)$ \\
\hline Vocabulary score & .41 & $.53^{*}$ \\
Reading score & $(.056)$ & $(.012)$ \\
& .41 & $.45^{*}$ \\
& $(.058)$ & $(.036)$ \\
\hline
\end{tabular}

$* \underline{p}<.05$ (two-tailed). 